6

$$
\begin{aligned}
& \text { ANL-HEP-CP-80-19 } \\
& \text { C.ONF-SO09142--1 }
\end{aligned}
$$

HISTORY OF THE SUPERCONDUCTING-MAGNET BUBBLE CHAMBERS

M. Derrick, I.G. Hyman, and E.G. Pewitt

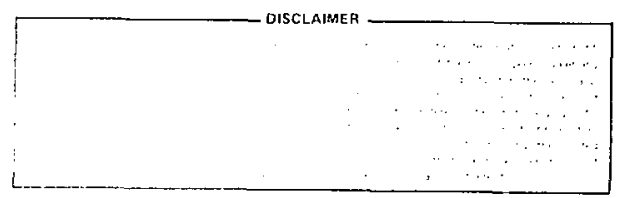

\author{
Prepared for \\ Symposium of \\ History of the ZGS \\ Argonne National Laboratory \\ Argonne, Illinois \\ September 13-14, 1980
}


The facilities of Argonne National Laboratory are owned by the United States Government. Under the terms of a contract (W-31-109-Eng-38) among the U. S. Department of Energy, Argonne Universities Association and The University of Chicago, the University employs the staff and operates the Laboratory in accordance with policies and programs formulated, approved and reviewed by the Association.

\section{MEMBERS OF ARGONNE UNIVERSITIES ASSOCIATION}

The University of Arizona Carnegie-Mellon University Case Western Reserve University The University of Chicago University of Cincinnati Illinois Institute of Technology University of lllinois Indiana University The University of Iowa lowa State University
The Unive;sity of Kansas Kansas state University Loyola University of Chicago Marquette University The University of Michigan Michigan State University University of Minnesota University of Missouri Northwestern University Uriversity of Notre Dame
The Ohio State University Ohio University

The Pennsylvania State University Purdue University Saint Louis University Southern Illinois University The University of Texas at Austin Washington University Wayne State University The University of Wisconsin-Madison

This report was prepared as an account of work sponsored by an agency of the United States Government. Neither the United States nor any agency thereof, nor any of their employees, makes any warranty, expressed or implied, or assumes any legal liability or responsibility for any third party's use or the results of such use of any information, apparatus, product or process disclosed in this report, or represents that its use by such third party would not infringe privately owned rights. Mention of commercial products, their manufacturers, or their suppliers in this publication does not imply or connote approval or disapproval of the product by Argonne National Laboratory or the United States Government. 
To be published in the Proceedings of the Symposium of the History of the

ZGS (September 13-14, :979).

\title{
HISTORY OF THE SUPERCONDUCTING MAGNET BUBBLE CHAMBERS
}

\author{
M. Derrick, L. G. Hyman, and E. G. Pewitt \\ Argonne National Laboratory
}

"It has been said that although God cannot alter the past, historians can. It is perhaps because they can be useful to him in this respect that he tolerates their existence."

Erewhen

Samuel Butler

\section{EARLY HISTORY}

In the late $1950^{\prime} \mathrm{s}$, a group of physicists at Carnegie Tech ${ }^{1}$ built a number of small bubble chambers for use with the $450-\mathrm{MeV}$ synchro-cyclotron facility that was located at Saxonburg, PA. Since bubble chambers were the dominant technique in studies of resonances and since those studies required the use of higher energy beams, it was natural for this group to consider continuing the work at the new $12-\mathrm{GeV}$ machine proposed for construction at Argonne. To this end, Tom Fields took leave from the University and came to Argonne in the fall of 1960 to work with Bob Thompson, who had joined the Laboratory from Indiana University. Thompson was charged with the responsibility of planning a bubble chamber construction program for the ZGS.

At that time the Berkeley 72 " chamber was being completed and so Thompson was thinking of something larger, perhaps as big as a $5 \mathrm{~m}$ bubble chamber. The major technical problem foreseen was the difficulty of obtaining a suitable glass window. The physics rational for such a large hydrogen chamber was not completely clear, but Fields and Thompson carried out optimization studies to explore the costs associated with different choices of chamber size and magnetic field. 2 However. Thompson was aware of the possibilities of using a large bubble chamber to do neutrino physics as the following quotation ${ }^{3}$ from a round table held at the 1960 Instrumentation Conference for High Energy Physics attests: ".... finally let me mention the possibility of using a large freon chamber for the neutrino experiments. The cost of a big magnet, the optical system, and the equipment to analyze the photographs is a substantial part of the total cost. The cost of the freon chamber would be only a small fraction. One has to remember that in a few years, neutrino physics may be one of the very hottest things, and a really large freon chamber detector for neutrinos would be a nice thing to have....." Shortly after this meeting, Thompson left Argonne for the University of Chicago. However, a cryogenic test building (829) had been provided, and the nucleus of a staff of 
technicians and engineers had been recruited. In early 1960, the Bell Laboratory group published a paper 4 describing the discovery of continuing superconductivity of $\mathrm{Nb} \mathrm{Sn}$ in a high magnetic field. As a result, the Argonne-CIT collaboration started the design of a small bubble chamber. The aim of the project was to build a device large enough to work usefully and competitively in the physics of elementary particles but small enough to have a reasonable chance of success. At best this promised to be a somewhat experimental device since no one could be sure that superconducting magnets would be practical, so the Laboratory, in collaboration with a number of users, proposed to copy the Brookhaven 80 -inch chamber as the quickest way of providing a large bubble chamber facility. This proposal was not supported by the AEC. A year or two after this, there was also an irformal proprosal from L. Alvarez to build two $5 \mathrm{~m}$ hydrogen chambers, one for SLAC and one for the ZGS. This idea was not greeted with enthusiasm by the Midwest university comi:iunity.

\section{SUPERCONDUCTING MAGNET DEVELOPMENT}

Following the publication from Bell Labs, Westinghouse issued a press release describing the operation of a superconducting magnet made of niobium/zirconium wire. The ANL-CIT group, which at that time consisted of Tom Fields, John Fetkovich, Ken Martin, and Gale Pewitt, solicited proposals to build a high field magnet to fit a round a 10-inch bubble chamber. Responses were received from Atomics International, General Electric, Magnion, Westinghouse, and Avco Everett. As a result of visits to all the vendors, and discussions with the people involved, Avco Everett was awarded a contract. 5 John Stekly from Avco made a great impression on the physicists in the group and seemed to understand many of the technical problems associated wi th such a venture.

Shortly after the contract was placed with Avco, Charles Laverick joined the group, and he and Tom Fields started a series of small experiments on superconductivity in order to build up some in-house expertise. They began making tests on short samples of wire and operated a number of small magnets that were wound in the lab. At that time, a liquid helium test facility was not the trivial thing it later became, and there was some period of learning how to design the cryogenic systems and transfer liquid helium without boiling it all away.

The conductor used in the Avco magnet was 10-mil $\mathrm{Nb} / \mathrm{Zr}$ wire with a very thin layer of copper on the outside, and one of the problems encountered was in making satisfactory electrical joints. The joint resistance depended on the orientation with respect to the magnetic field. As a result of a development effort at Argonne, a double parallel joint was developed, using both a crimped copper tube and a $\mathrm{Nb} / \mathrm{Zr}$ block. This technique gave a resistance of $<1 \mu \Omega$ at $30 \mathrm{kG}$ when aligned parallel to the field. 6 We had a technician, called Joe Bozman, who became very good at making these joints, and we sent him to Avco to make the joints for the magnet.

The magnet, shoivn in Fig. 1, was made of a stack of pancakes; 


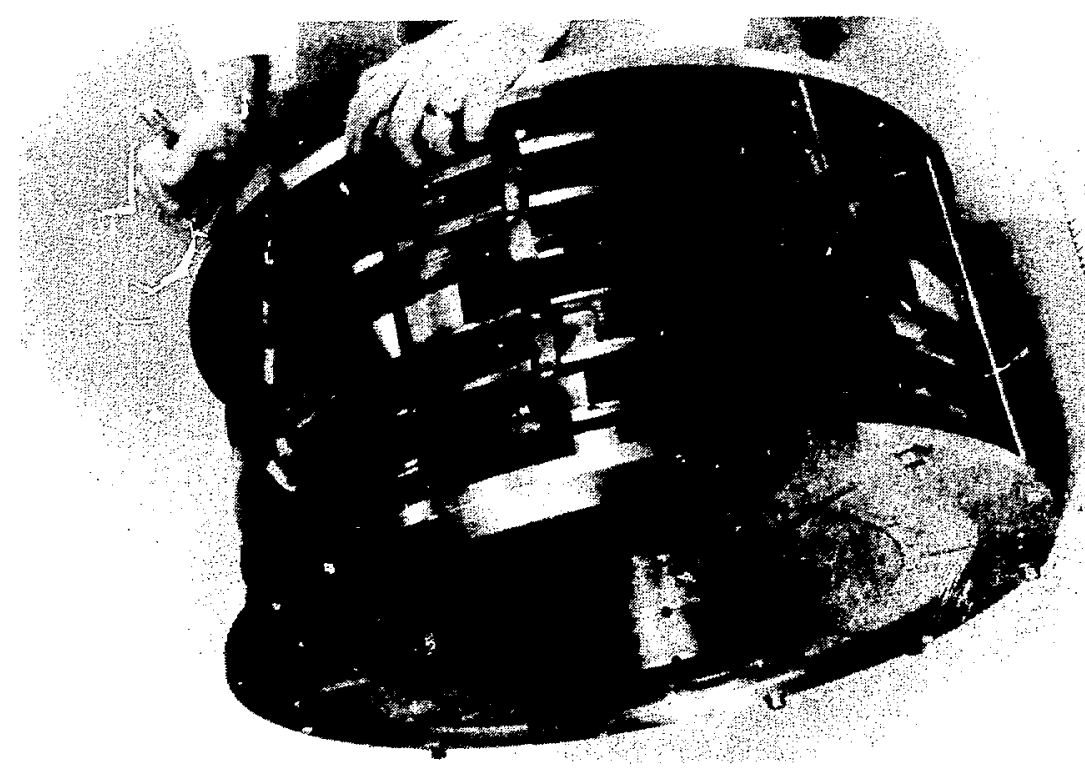

Fig. 1 AVCO magnet coil package.

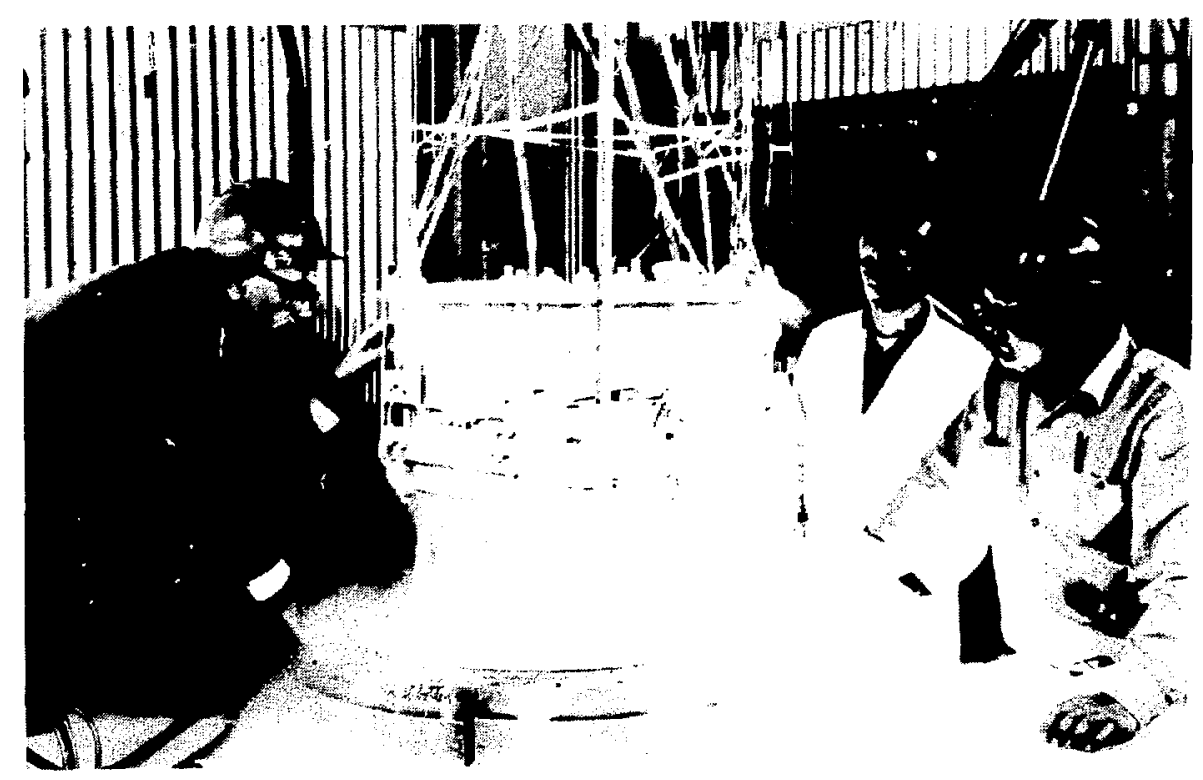

Fig. 2 Argonne magnet being withdrawn from the test dewar. 
the most impressive thing was that it used a total of $4_{s} 0$ miles of $10-$ mil wire, givirg an inductance of $7,000 \mathrm{H}$. Each pancake was layerwound with external shunts placed every second layer. Shorted copper rings were used between layers to control the time constant of current decay during a quench. Much of the energy was dissipated in the external shunts. 7

After one or two of the eight pancakes were wound, the job slowed down at Avco, and no progress was being made. We later learned that Stekly had developed a copper-stabilized conductor, and the company had no enthusiasm for proceeding with our contract. There was a showdown between Charlie Laverick and Arthur Kantrowitz, the head of the Avco Laboratory; Stekly at the time was in Florida on vacation. To accelerate work on our magnet, Charlie threatened to send a truck to pick up the remaining pieces and said we would finish it ourselves. This bit of gamesmanship forced Kantrowitz to have Stekly come back from Florida and work full time on the project. The magnet was completed and tested at Avco. It carried $11 \mathrm{~A}$ giving a central field of $32.8 \mathrm{kG}$. We used most of the helium on the eastern seaboard in the test.

By this time it was clear to everyone that developments of the art had made this prototype obsolete. The magnet was quite unstable, and so not suitable for use in a complicated experiment where reliability of every component was required.

As a result of the work on the Avco magnet and other ideas, it became clear in which direction to go in order to build a more reliable magnet. The quality control in the early superconducting material was not good, so the technique of using a single strand of conductor as the only path of the current meant that one small bad section could limit the current-carrying capacity of a whole pancake. Another problem came from the use of epoxy resin to hold the wires. The poor thermal conductivity of this material made it difficult to provide adequate cooling in the middle of the coil.

The solution of these difficulties was to make a composite conductor consisting of many rarallel superconducting strands in intimate contact with a normil material. Charlie Laverick developed a conductor that was made by cabling several strands of superconductor and copper and impregnating the resulting cable with indium. George Lobell designed a machine to make the cables in the Argonne Central Shops. This simple technique allowed a wide variation in the fraction of copf ir and superconductor, and also meant that each superconducting strand followed a helical path; the importance of which we did not immediately realize. Good cooling was provided by using stainless steel mesh between layers of the magnet.

On the first test, the new magnet ${ }^{8}$ gave a central field of $44 \mathrm{kG}$ and behaved in a very stable manner although the strong inductive coupling between the different sections which were on separate power supplies challenged our understanding of Lenz' law. A liner of 7inch bore was installed in the magnet for the first test in a helium dewar and when this inner section was energized, a field of $67 \mathrm{kG}$ was obtained. Fig. 2 shows this magnet being withdrawn from the test dewar. It is now on display at the Smithsonian Institution in Washington. 
It was then just a matter of installing the magnet in its cryostat and testing the whole system - not such a simple matter as the cryostat had a removable end plate with large indium seals and it took some time to make these leak-tight.

\section{SMALI BUBBI,E CHAMBER CONSTRUCTION}

In parallel with the work on the magnet, the bubble chamber was being designed and built. At the time, we had anticipated a long program of physics, and so the chamber was designed to operate with hydrogen or deuterium as well as helium. This meant that the chamber, as shown in Fig. 3, ended up being a ratier complicated device.

In order to conserve magnetic field volume, the flanges and windows of the chamber were placed beyond the magnet, resulting in a rather deep chamber. The chamber vessel itself was a thin-wall stainless steel cylinder machined eccentric tc have a thicker wall section at the top than the bottom. Cooling channels were machined in this top section and capped with a copper plate. There was considerable difficulty in fabricating this piece as the cylinder always distorted when the copper insert was brazed onto the wall. We finally had a second chamber body made in which the copper was electroformed onto the steel.

The illumination of a long cylinder for dark field photography presented a special problem. It is desirable to have the light from the source focus at the camera plane so that the scattered intensity to each camera from bubbles anywhere in the chamber is roughly constant. Fig. 4 shows the illumination system that was designed by John Fetkovich. There were two cylindrical reflectors (one of which was the wall of the chamber itself), that produced an intermediate vertical ring source, which was then imaged by the plastic lens window of the chamber at the camera plane.

The expansions were made by using the condensing lens as a moving wall of the chamber. The Plexiglas lens was sealed to the chamber body by a stainless steel omega bellow's. Because of the large expansion coefficient of plastic, a special plastic-metal seal had to be developed that was later patented. 9 A complete expansionrecompression cycle took $15 \mathrm{msec}$. The cryogenic systems were complicated by the fact that both liquid nitrogen and liquid hydrogen heat intercepts were used on all support members to reduce the heat input to helium temperature. Two separate helium systems were used. Since the chamber operated at about $3.2^{\circ} \mathrm{K}$, the chamber cooling was done using helium under reduced pressure. The magnet was cooled by helium slightly above atmospheric pressure.

In August 1963, a proposal was submitted to the ZGS Program Committee. The title page of what became ZGS Experiment 12 is shown as Fig. 5. 10 It is notable that Tom Fields was the only physicist on the proposal with a tenure job. In the proposal, we emphasized the importance of good momentum resolution. For low momentum particles, the relevant parameter is $\mathrm{B}^{2} l$, where $l$ is some typical track length, and in this parameter, the chamber was superior to any other chamber then operating with the exception of the Berkeley 72 " bubble chamber. 


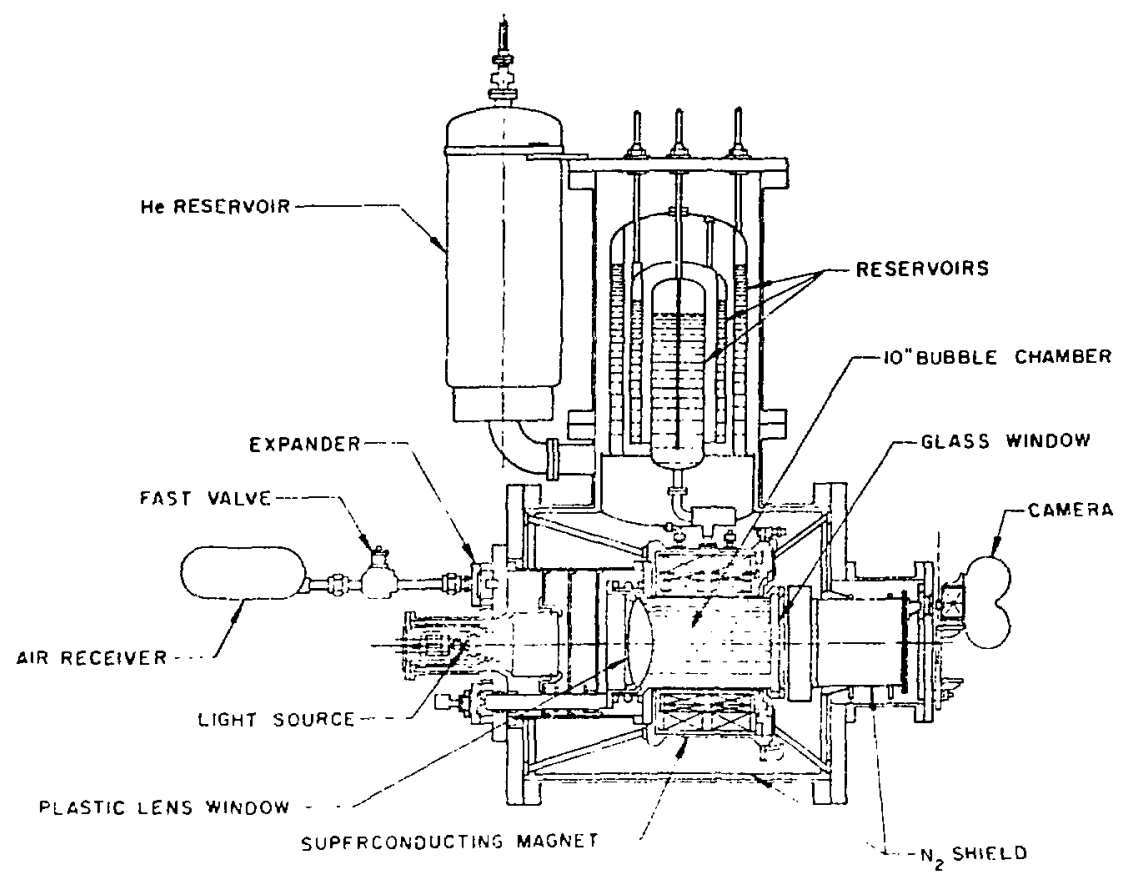

Fig. 3 Superconducting magnet bubble chamber assembly.

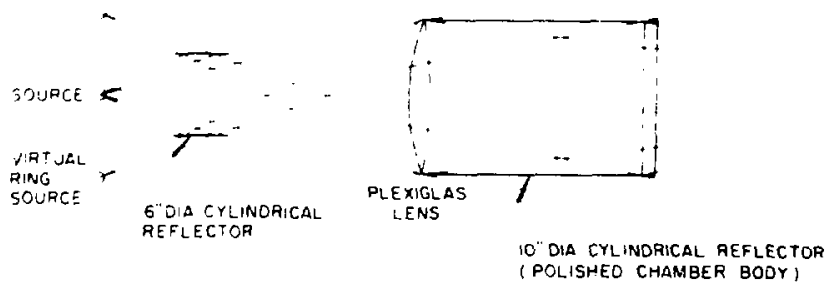

$-\div$

0

$=0$

Fig. 4 Ray diagram of illumination optics. 
A RGONNE NATIONAL LABORATORY

Argonne, Illinois

August 30, 1963

1. EXPERIMENTS WITH STOPP'NG KAONS IN HELIUM AND ANTIPROTONS IN DEUTERIUM

2. EXPERIMENTERS

A. Ph. D's:

Carnegie Institute of Technology

J. G. Fetkovich, Assistant Professor

J. McKenzie, Research Physicist

E. G. Pewitt, Assistant Professor

Argonne National Laboratory

M. Derrick, Assistant Physicist

T. H. Fields, Associate Physicist

L. G. Hyman, Assistant Physicist

B. Students: Several students at Carnegie Tech will help in the data reduction.

C. Engineers:

C. Laverick, Associate Electrical Engineer, ANL

K. B. Martin, Associate Cryogenic Engineer, ANL

S. Stasak, Electronics Engineer, CIT

D. Technicians:

J. Santori, Technical Assistant, ANL

C. Barnes, Senior Technician, ANL

J. Sheppard, Senior Technician, ANL

F. Piotrowski, Senior Technician, ANL

P. Arvidson, Research Technician, ANL

J. Griffith, Senior Technician, CIT

J. Sadecky, Laboratory Technician, CIT

C. Petrigni, Laboratory Technician, CIT

Fig. 5 Proposal for E12. 
A separated, low momenturn ka on beam was needed in order to provide a source of stopping $\mathrm{K}^{-}$. The beam that was built is shown in Fig. 6. It used conventional two-stage optics, each stage having a $10-\mathrm{ft}$ long electrostatic separator. Positive particles were taken off at $28^{\circ}$ from an internal target, whereas negative particles could be used at smaller production angles depending on the target position inside the ZGS octant.

At ZGS turnon, the meson shield wall had a simple unseparated beam at $30^{\circ}$ that was used for studies of hypernuclei and $\mathrm{K}^{\circ}$ decay by the Northwestern-Argonne and Illinois groups, respectively. The shielding round the three beams coming from the internal target was fairly complex and so there was some reluctance on the part of the management of the Particle Accelerator Division to change the arrangement in the meson cap as it was called, but finally in late 1965, the change was made and the separated beam installed. The bearn was tuned and behaved as expected although the intensity was less than that predicted.

There was some difficulty in the beginning of the experiment in centering the beam in the chamber, and the last quadrupole had to be moved by about 1/4-inch to steer the beam horizontally. It later turned out that bending magnet $B 2$ in the beam was misplaced by one inch from the nominal position. Fig. 7 shows the helium chamber installed at the end of the $28^{\circ}$ beam in the meson building before the camera plate was put on.

This beam was also used later to provide particles for the Michigan-Argonne heavy liquid chamber and the Northwestern helium chamber.

Just before our run took place, there was a proposal from the Northwestern group to use their $20^{\prime \prime} \times 10^{\prime \prime} \times 10^{\prime \prime}$ helium chamber instead of the supermagnet chamber to carry out the physics program of $\mathrm{K}^{-}$in helium, and, indeed, throughout our exposure, the Northwestern chamber was on standby at liquid nitrogen temperature waiting for us to break down! Fortunately, the problems anticipated by our competitors did not materialize and in the period March 5-29, 1966, 476, 800 photographs were taken. The run summary is given in Table I. It was compiled by Gary Keyes, a student who did a Ph. D. thesis studying the properties of hypernuclei produced in $\mathrm{K}^{-}$He interactions.

A competition developed between the physicists on the different shifts to see who could take the most pictures. This placed a pre mium on devising an optimal strategy of transferring helium from the 1000-liter storage dewars into the chamber reservoir. Several physicists were also known to have advanced the cameras manually when the automatic film advance failed.

We took some pictures of stopping $\mathrm{K}^{+}$as we wished to use the $\mathrm{K}^{+}-\pi^{+} \pi^{+} \pi^{-}$decay as a calibrator of the magnetic field and also a few pictures of stopping antiprotons to see if there was any physics in $\bar{p}$ He reactions. The latter had not been approved, and the management of the Particle Accelerator Division had a strong reaction to this minor infringement of the rules. 
Table I Summary of 10-Inch Helium SBC Run March $5-29,1966$

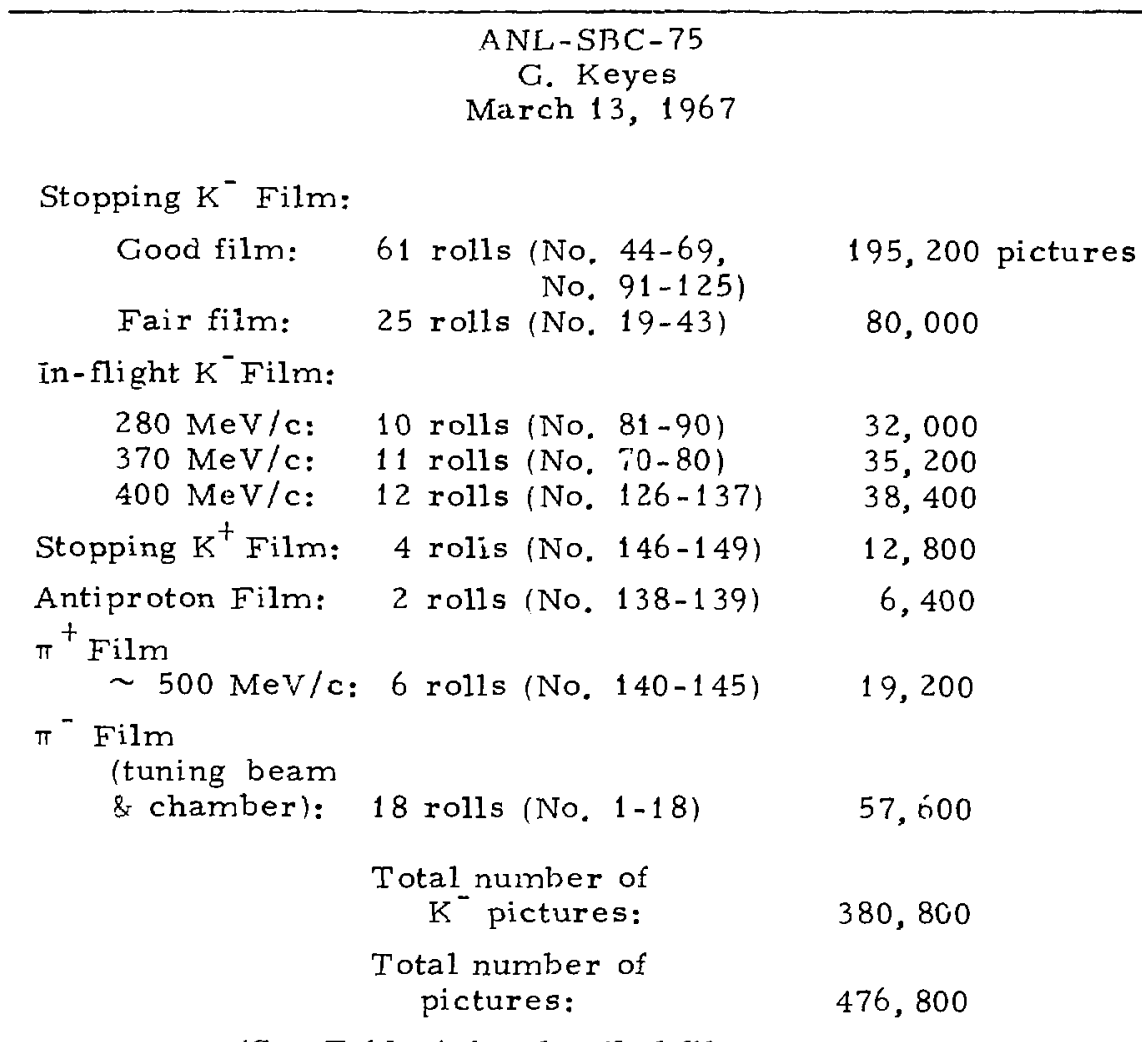

(See Table 1 for detailed film summary.)

Aver $\begin{aligned} & \text { Rolls } 45-149 \\ & \text { jee Table } 2 \text { for detiiled sum }\end{aligned}$

VPT-1 $231 \mathrm{~mm}$ 。 Hg. see Table 2 for detuiled summary.) VPT-2 $245 \mathrm{~mm}$. Hg. Overpressure: $305 \mathrm{~mm}$. Hg. ZGS Intensity: $4.3 \times 10^{\prime \prime}$ protons/pulse

Liquid Consumption:

$\begin{array}{ccc}\text { Helium: } & 420 & \text { liters/day } \\ \text { Magnet: } & 270 & " 1 \\ \text { Chamber: } & 150 & " \\ \text { Hydrogen: } & 270 & \text { " }\end{array}$

Magnet Current Regulation: Maximum fluctuation:

Standard deviation: 


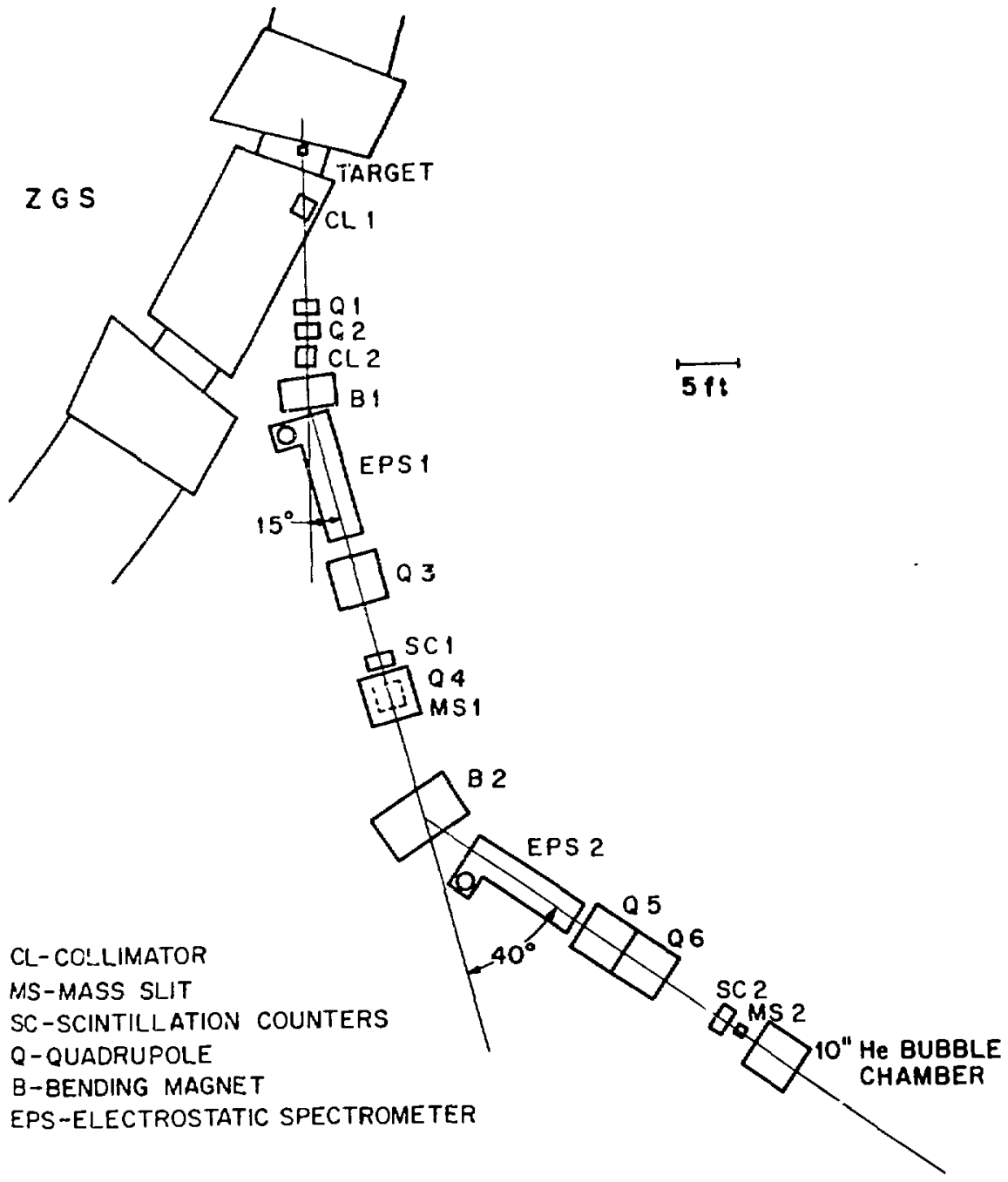

Fig. $628^{\circ}$ low momentum separated beam. 


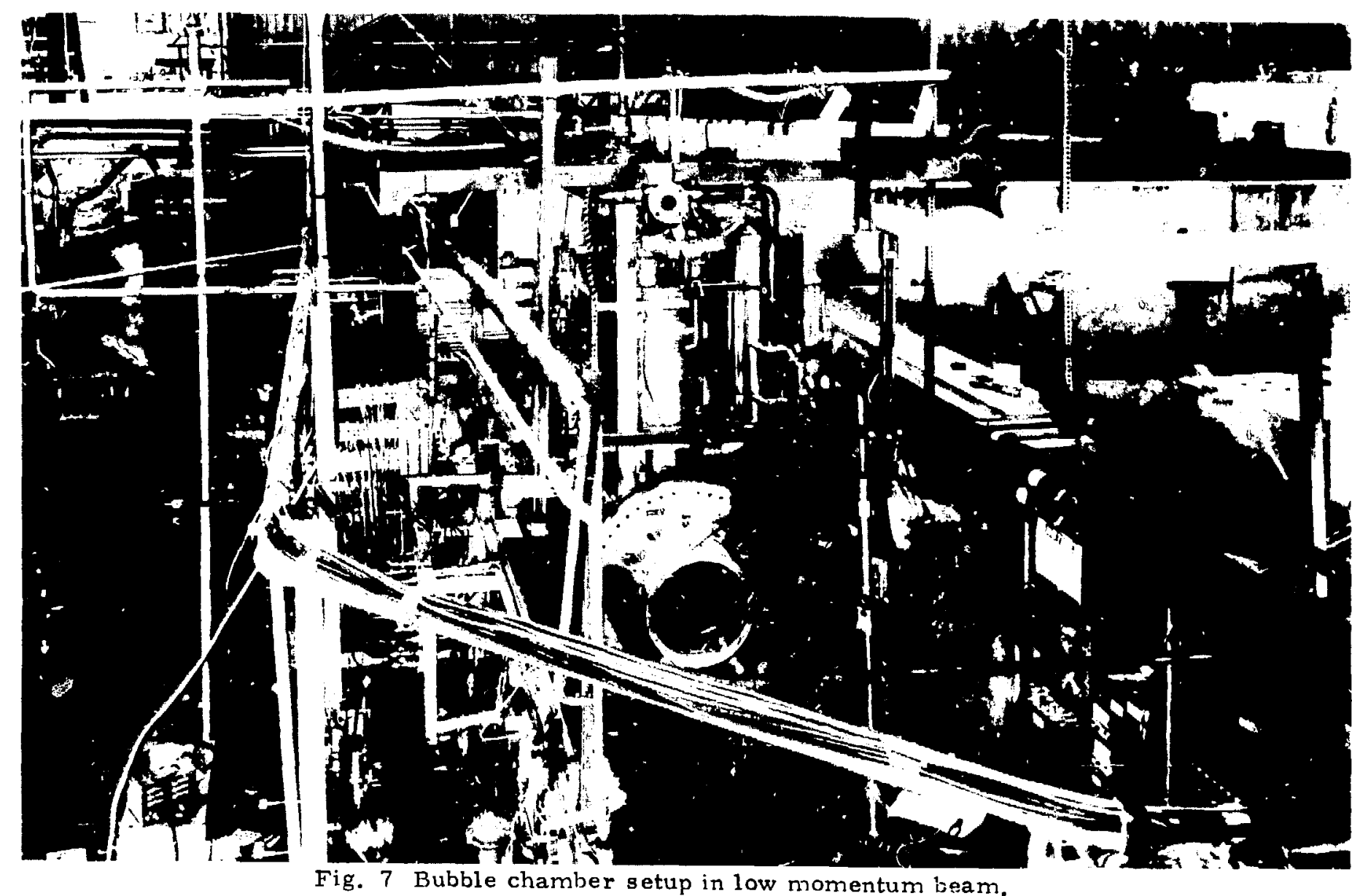




\section{HIGIT FNERGY PIYSICS RFSITITS FROM THF, SMAI,I CHAM:3FR}

We immediately set to work to do the physics analysis. In addition to the $\mathrm{K}^{-}$pictures, we had also taken some film of low energy pions for a Kansas group, and the IIT group approached us about doing some irdependent analysis using the $K^{-}$film, so that with the Argonne and Carnegie efforts there were four groups working on the analysis.

The chronology of the program and, in particular, the physics publications, is shown in Table II. A total of six Letter putlications and 10 articles resulted from the work, and the total program from first discussions to final publication extended over about 15 years. It is not appropriate to discuss the physics in detail, but it was notable that many experimeits were done that were not anticipated in the proposal.

An early result oi some importance was a measurement of the lifetime of the hypernucleus $\mathrm{H}^{3}$ where we showed that the lifetime wis in accord with theory and in disagreement with an earlier measurement. We also did a number of other studies of the light hyper. nuclei $\mathrm{H}^{3}, \mathrm{H}^{4}$, and $\mathrm{He}^{4}$ and many of the results were presented at an International Conference on Hypernuclear Physics held at Argonne in 1969 and organized by A. Bodmer and L. Hyman.

The chamber also proved to be a rather accurate device. We made the best measurement of the range-energy relation in helium, and this precise calibration, combined with the high magnetic field, allowed us to make good measurements of the $I^{\perp}$ and 1 masses and give an improved upper limit on the $v^{\prime}$ mass. In addition, we made systematic studies of many reactions ' $\mathrm{resulting}$ from $\mathrm{K}^{\text {' }}$ interactions in helium - something that had not been done previously.

\section{EARIY HISTORY OF THE TWELVE-FOOT BUBBLE CHAM $3 E R$ PROJECT}

In late 1963, a group from Madison led by Jack Fry and Ugo Camerini proposed to build a large heavy liquid bubble chamber to be used to study neutrino physics at the 7.GS. Although somewhat smaller, the parameters were very similar to the Gargamelle chamber that was later so successfully operated at CERN. Wilson Powell worked with the group and built a 2 -ft model chamber to test various parameters of the final project. After the construction of the 12 foot hydrogen chamber was approved for Argonne and as a result of the progress of the Gargamelle project, the Wisconsin group proposed in 1966 to locate their heavy liquid chamber at the AGS, but this was not accepted by the Brookhaven management. The magnet for the chamber was built. and later used as the basis of the Multiparticle Spectrometer at Brookhaven. The chamber project was then terminated. The decision not to continue with the Wisconsin chamber was influenced by the realization that a hydrogen bubble chamber could be operated with neon and so do mich of the physics accessible to a heavy liquid chamber. 


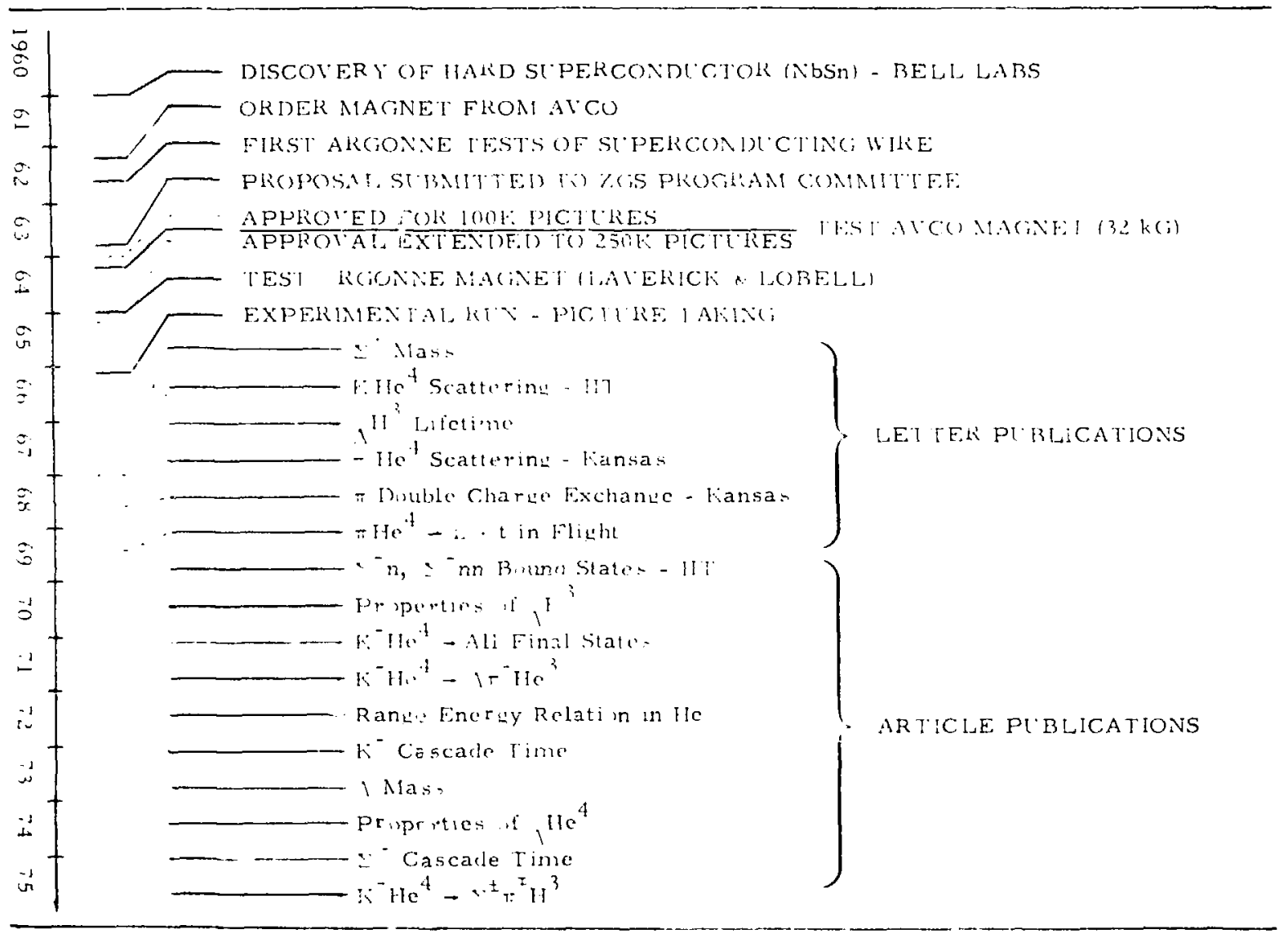


(HEDG) meeting at which large bubble chamber proposals would be discussed. Two proposals were presented at that meeting. Bob Palmer described a proposed sixteen-root hydrogen bubble chamber and a number of considerations were presented, which Palmer felt illustrated that a chamber was feasible on this large a scale. The other proposal was by Mel Schwartz and Jack Steinberger of Columbia for a scaled-up version of the $30^{\prime \prime}$ hydrogen bubble chamber built at Nevis. The Columbia proposal appeared to be very preliminary and it was not clear, for example, if any magnetic field calculations had been made. The proposal was perhaps intended to ensure the Columbia groilp would be a lead user of a large chamber if it were built.

Later that year an AUI Committee was appointed under the chairmanship of Dave Frisch of MIT to resolve the conflict. We met with this conmittee in New York to discuss the 12-ft chamber project and combined this business with an interesting visit to the World's Fair. The outcome of the Frisch committee was to scale down the $B N L$ proposal to $14 \mathrm{ft}$ and to insist that it be a facility available to all users on the basis of competitive proposals.

Following the HEDG meeting and after discussions between the Argonne high energy physicists, Gale Pewitt was asked by Roger Hildebrand to develop a proposal for a large chamber to be used at the $/, G S$. A small proposal team was assembled, and we hired Peter VanderArend as a cryogenic consultant. We were assigned a designer and started putting together some preliminary ideas.

The major question was the optics of the system. Both the BNL 14-ft chamber proposal and our plans called for the use of sniall windows, and these depended on being able to use Scotchlite as a retrodirector for the light. The Wisconsin group had earlier chosen this solution for their proposed heavy liquid chamber. The technique had been used successfully in small heavy liquid chambers, but it was not known if it would work in liquid hydrogen. Two different types of Scotchlite were obtained (the blue open-bead type and the green covered-bead variety) and tested at Carnegie-Tech in a six-inch hydrogen chamber. Some Cobalt-60 Compton electrons were photographed in liquid hydrogen and pictures of these tracks were shown in ou: proposal as a proof that the system was practical. The proposal was completed in June 1964 and submitted to the AEC. The title page is shown in Fig. 8.

The Laboratory also had an FY 1966 proposal jointly prepared by the MURA and Argonne accelerator groups to build a $200-\mathrm{MeV}$ linac as a new injector for the Z.GS. In July 1964, the Users Advisory Committee met at Argonne to discuss the relative priority of the bubble chamber and the linac. The committee included, among other people, Bill Walker and Ned Goldwasser. They failed to agree, and the Argonne management gave first priority to the bubble chamber and the new external proton area (Building 375). It was interesting to note that the 3 rookhaven users recommended that their linac system be put first in priority and the bubble chamber second.

There were some vigorous discussions about where the project wruld be located within the 7.GS Complex. The proposal work had all ieen done by physicists and engineers within the High Energy Physics $r$ sion under the general direction of Tom Fields, the Division sictor, but most of the engineering talent was in the Particle 


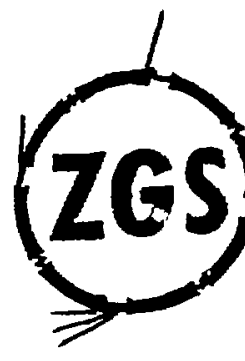

\section{PROPOSAL \\ FOR THE CONSTRUCTION OF A 12 FOOT HYDRCGEN BUBBLE CHAMBE?}

$p$

June 1964

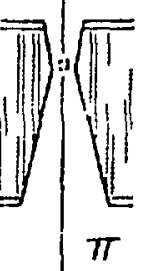

Thi-prepisal wa: prepared by:

.H. Der rick, Arunne Nati,nal Laburatury

$\because$ 1!. Fielde. ANL an' Northwe:tern lniver rity

T. C. Fetkowch, Carnegie Institute of Technosiog

K. P Martin. Arunne Natunal Laburatory

F. C. Pewitt, ANL and Carneuie Inst. if Technolosy

A. Tamusaitis, Argonne Natiunal Laburatury

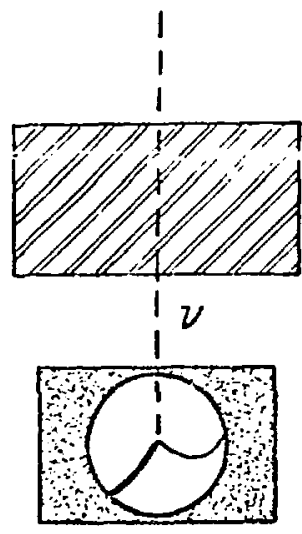

Fig. 8

Argonne National Laboratory 
Accelerator Division. Bob Sachs decided that the HEP Division would build the chamber with engineering support from PAD, and Lee Teng assigned some very good people to the project.

When the President's budget for FY 1966 was announced on January 20, 1965, the 12 -fuot bubble chamber was included as a line item. In addition to the bubble chamber, the extraction system and experimental a rea which became EPB-II was also funded for a total of about $\$ 17 \mathrm{M}$. For Brookhaven, a $200 \mathrm{MeV}$ linac and the AGS improvement program was supported at about $\$ 50 \mathrm{M}$, but not the 14-ft bubble chamber.

We dor't know all the political factors which resulted in the 12 foot chamber being included in the President $s$ budget, but it is significant that MURA was phasing out at this time, and there was strong Midwest political pressure for facilities that would be competitive with the East and West coasts.

Before we knew about the construction approvai, two of us went to California to discuss the proposal with Luis Alvarez. He listened to us for about thirty minutes and then told us that in projects like this, you've got to work on the politics as well. He thought we had already put too much work into the technical side, and that we should concentrate on getting political support for the chamber. He also said we ought to see Bill Brobeck and get him to do a cost estimate of the chamber. Alvarez felt that the AEC would request an independent cost estimate, and that we should beat them to it. We took this advice, and before we left the building, we called Bill Brobeck, made an appoiniment, and left a copy of the proposal with him. Some time later, Brobeck visited Argonne. He put the proposal down and said, "Our estimate is that, based on the proposal and our discussions, it will take ten million dollars to build, but it will cost you ten thousand dollars to get this in writing!"

We wrote a contract and Brobeck as signed Carl Skabalsky to the job of confirming our cost estimate. Skabalsky wrote a number of letters and received quotes that added up to less than our estimate, so we supplied him with more information which made his estimate come much closer to ours.

\section{TECHNICAL DECISIONS}

In the proposal we had suggested the use of a large diaphragm to expand the chamber. When we got down to detailed design, the difficulty, if not impracticality of this, became clear. We decided to go to a larger version of the omega bellows that we had used for the 10-inch chamber, but this time located at the bottom of the chamber with photography done from the top. Thare was some controversy over whether having the cameras looking directly at the expansion system was advisable. Since no one had experience in the thermal design of large chambers, we also had real concern aboul photographing through many feet of liquid hydrogen.

To minimize these problems, we decided that the cooling of the chamber would be clone behind a shroud, which would be located in the chamber and spaced oif from the wall by a few inches. This shroud prevented the cold liquid from the heat exchange $r$ from falling 
into the photographed volume.

Cooling loops we re installed to intercept all the conduction heat leaks to the chamber. The heat added, due to irreversible expansion, was to be removed at the top. The design of this copperfinned heat exchanger underwent many changes before it was finally built and installed.

The cameras were to be located at some radius from the center of the chamber, whether at the full diameter or at some intermediate diameter, was left undecided. A point that we quickly realized was that flat windows would not work. Because of the dispersion of the liquid hydrogen if the light rays entered the glass at other than normal incidence, the image would be smeared. This smearing would amount to as much as $5 \mathrm{~mm}$ for a $45^{\circ}$ angle of incidence. This problem could be overcome either by going to a very small bandwidth on the light source or by using a hemispherical fisheye window. We chose the latter solution.

It was decided to view the chamber volume with four cameras arranged on a square. The exact location of the camera windows received considerable attention. There was a strong desire to locate the cameras near the axis of the che nber, thereby greatly enhancing the ease of scanning the film, in that the stereo views would look very similar. On the other hand, there were arguments for placirg these cameras at the edge of the chamber, so as to maximize the stereo angle, improve the measurement precision, and maximize the volume of iquid covered. Ray Ammar wrote a program to generata events as seen through cameras placed at different locations. The resulting film was scanned by a number of physicists. As a result of this exercise, we located the cameras at a compromise location about half way out from the center.

We decided to build a model of the chamber in order to test the optical turbulence problems and to meastre the specific dynamic heat load. The latter was not well known as the heat load of the existing chambers was dominated by boiling round the window seals and at the expander. The model was two feet in diameter but had many features in common with the full-size device.

Work proceeded in building the model, and Lyle Genens developed a procedure for forming the large bellows. The procedure utilized some of the features employed by the Badger Fire Extinguisher Company of Lowell, Massachusetts, who made bellows for expansion joints. We modeled the bellows formation on a twofoot diameter scale, and formed a number of bellows that we re used for other applications, including the two-foot chamber.

Jack Frolich was the engineer in charge of putting the two-foot chamber together. It was assembled first in Building 362, and then was moved to Building 829 and operated there. Stan Stoy and Mike Morgan also worked on the job. The results of these tests convinced us that the dynamic heat load on the 12 -ft chamber would be manageable and that the rmal turbulence would not dominate the precision of reconstruction.

The expansion system that we built for the two-foot chamber was a state-of-the-art system. We contracted with an English engineer by the name of Brian Wolfington. He lived in Billerea, Massachusetts, and had his shop in a house built in the 1700's. 
Tony Tamosaitis was the Chief Engineer of the bubble chamber, and it was through him that experts in the relevant technology areas were located. The turbulence problem was examined, and we talked with a professor from the Computing Department of Purdue University to ask him if he would study the problem. He said it would take enormous computing time to calculate the shift of a spot due to heat flux through 12 -feet of hydrogen. He also pointed out to us that we didn't really want consulting; we wanted laborers, and that was not suitable to a university professor. Tony also contacted Dave Fultz from the Ceophysics Department of the University of Chicago. We visited him and described the problem. We told him that we we re building a model chamber, and he asked the dimensions. We told him a two-foot model, and he said, "Do you mean to tell me that you want to build a twelve-foot chamber and you wili model it on a two-foot scale?" "I'm used to scaling by factors of $10^{5}$ or $10^{6}$; sounds lite you people are going to make an actual mea surement!" we were much encouraged by his comments.

One of the pleasures of the whole job was developing new systems. We chose the expander to be a resonant hydraulic system. The calculations we re checked by Larry Turner and Richard Hoglund, a professon of hydraulics at Puidue University. The find design for the expansion system was riade by Jim Simpson with help from Lyle Genens and Norm Majeski. Simpson's approach was that everything had a. simple soiution; that sort of confidence was certainly highly beneficial.

We had John Purcell visit for a couple of weeks of consulting to look at the transient problems in the superconducting magnet $f_{n} r$ the 10-inch rhamber. He attacked these problems quite well, so we hired him for the 12 -ft project.

He was assigned to work in Charles Laverick's laboratory and was also charged with the design of the 12 - $\mathrm{ft}$ superconducting magnet. John Purcell, who had worked on cryogenic magnets, quickly appreciated the concept of cryogenically stable superconductors that had resulted from the work on the 10 -inch chamber. In parallel, a conventional magnet coil was designed by Ray $\mathrm{Krizek}$, an engineer in the Particle Accelerator Division. The iron yoke of the magnet was designed by Jim Bywater with help from Jack Nolan and Pete Marston of Magnetic Engineering Associates.

In June of 1965, we had to decide whether to go with a conventional magnet or with superconducting coils. The magnet iron was designed to be compatible with either. This was a very exciting ques tion. The cost estimates of the two alternates were almost identical. The saving was in the operating cost of the superconducting magnet. We received a lot of alvice, and probably the pivotal aspect of the whole matter was that the superconducting magnet was such a challenging frontier device it attracted high quality people. As a result, it was easy to see that we could do a better job on the superconducting magnet than we could on the conventional magnet. In the event the decision turned out to be correct and the superconducting magnet provided the practicality of the new technolrgy on the largest scale. I1 Fig. 9 shows the magnet coils under construction. 


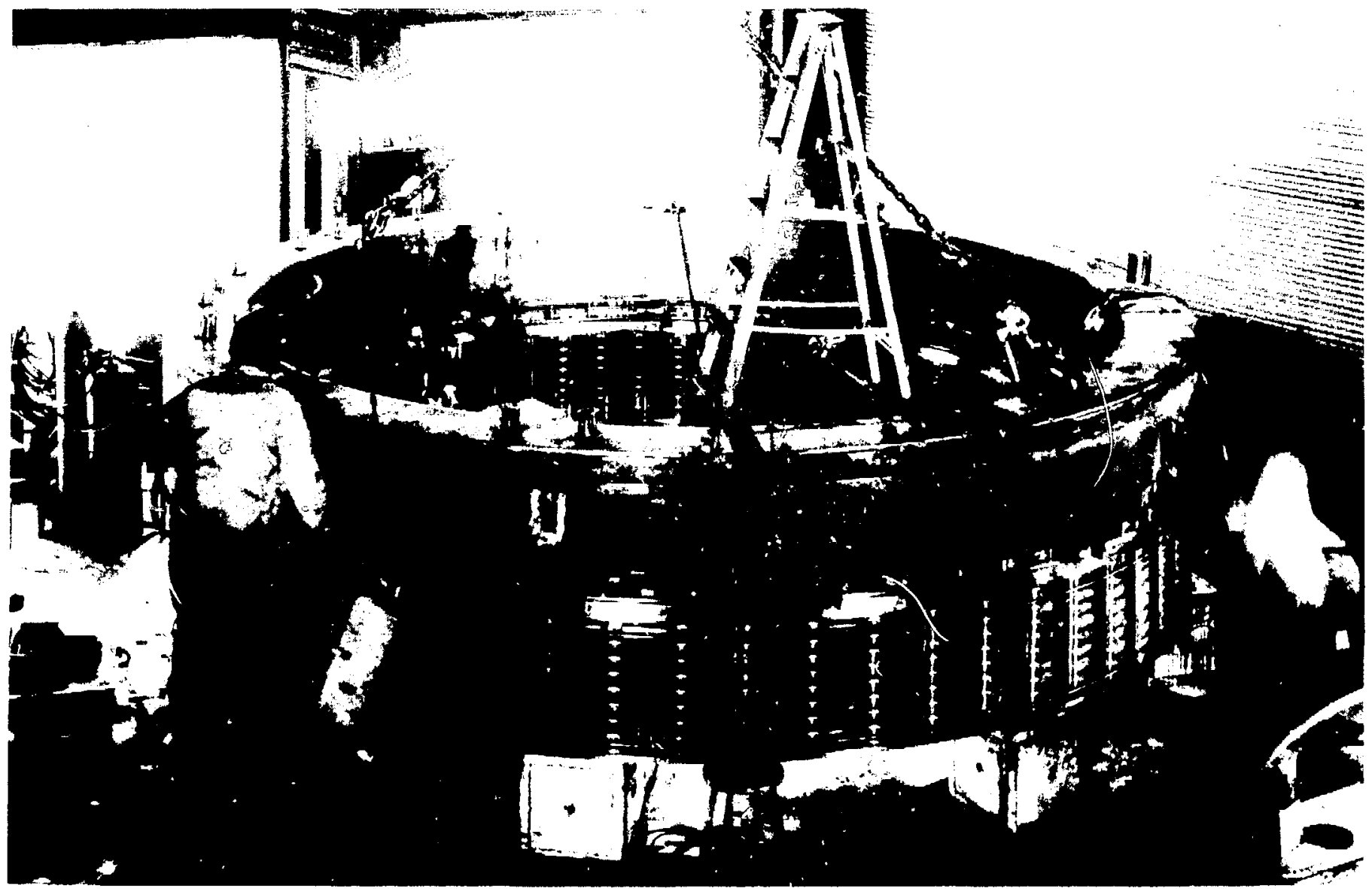

Fig. 9 Assembly of Superconducting Coils 
IABIEE III I FIHHC CONSIRICTION SCHEITLE

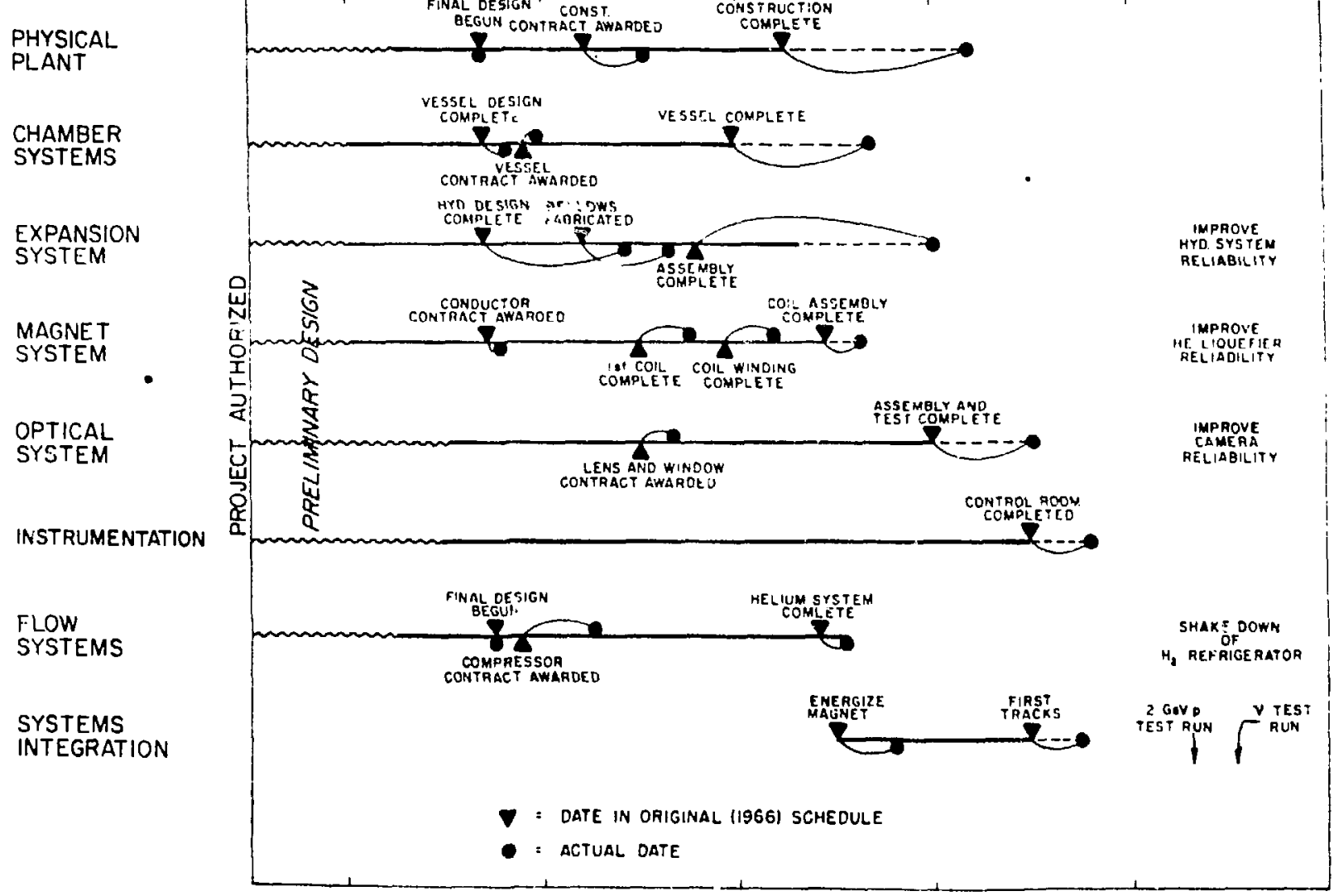


The conductor used in the magnet consisted of six strands of $\mathrm{Nb} \mathrm{T} i$ extruded in a copper matrix into a strip ?." $\mathrm{x} 0.1$ ". This technique is now standard, but many more thinner filaments of superconductor are used and the filaments are arranged to follow helical paths to avoid eddy current in the subatate that can have long time constants. These problems did not affect the magnet of the $12-\mathrm{ft}$ chamber since the iron yoke shaped the field to be solenoidal. In the 10 -inch chamber by cabling the conductor, we also avoided this problem of persistent eddy currents.

\section{CHAMBER CONSTRUCTION}

The construction schedule is shown in Table III as it was originally projected, and as it actually turned out. 12 It is notable that one of the longest slippages occurred in the conrentional construction of the physical plant, although there was also a similar delay in the fabrication of the chamber vessel.

Lyle Genens and Bob Kleb were the principal mechanical engireers in the design and construction of the bubble chamber. Fig. 10 is a picture of the chamber vessel before insertion in the magnet. The 19,000-1b. pistor is shown in Fig. 11 .

The cryogenic design of the chamber and the refrigeration systems was provided by a consultant, Feter Vander $A_{\text {r end, with the }}$ assistance of Stan Stoy of the Argonne staff. The major challenge was to intercept all heat leaks and, of course, to have a chamber with a design of the internals which minimized the boiling during expansion.

The system, as it was finally built, is shown in Figs. 12 and 13. $T^{\prime} \geq$ reconstruction accuracy achieved was $300 \mu$ in space, corresponding to $\Delta p / p-1 \%$ for all momenta up to $12 \mathrm{GeV} / \mathrm{c}$. A photograph of a typical $v p-\mu^{-} p \pi^{+}$neutrino interaction is shown in Fig. 14. Some typical operating conditions are listed in Table IV.

Table IV Typical 12 -Foot HBC Operating Conditions

$\mathrm{T}_{\mathrm{H}}=25.7^{\circ} \mathrm{K}$

$V P=3.72$ atm. abs. $(=40$ psig $)$

Static Pressure $=4.8$ atm. abs. (= 55 psig)

Expanded Pressure $=1.2$ atm. abs. (= 33 psig)

$\Delta V / V=0.67 \%$

Piston Stroke $=19 \mathrm{~mm}$

$\oint \mathrm{PdV}=3000 \mathrm{~J} /$ pulse $\approx 0.1 \mathrm{~J} /$ liter per pulse

Pressure Wave Form

$40 \mathrm{msec}$

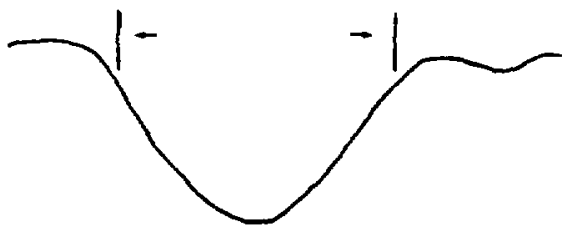

Flash Delay After Beam $=4.6 \mathrm{msec}$. 


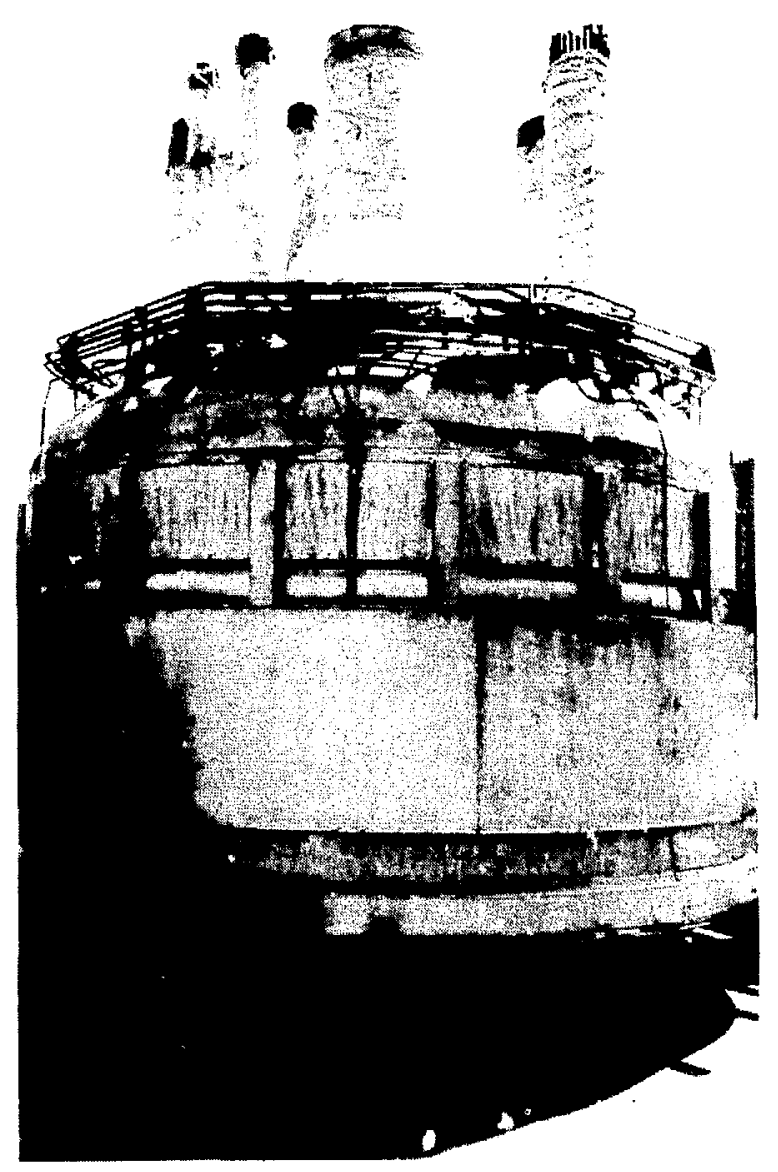

Fig. 10 Chamber vessel ready for installation.

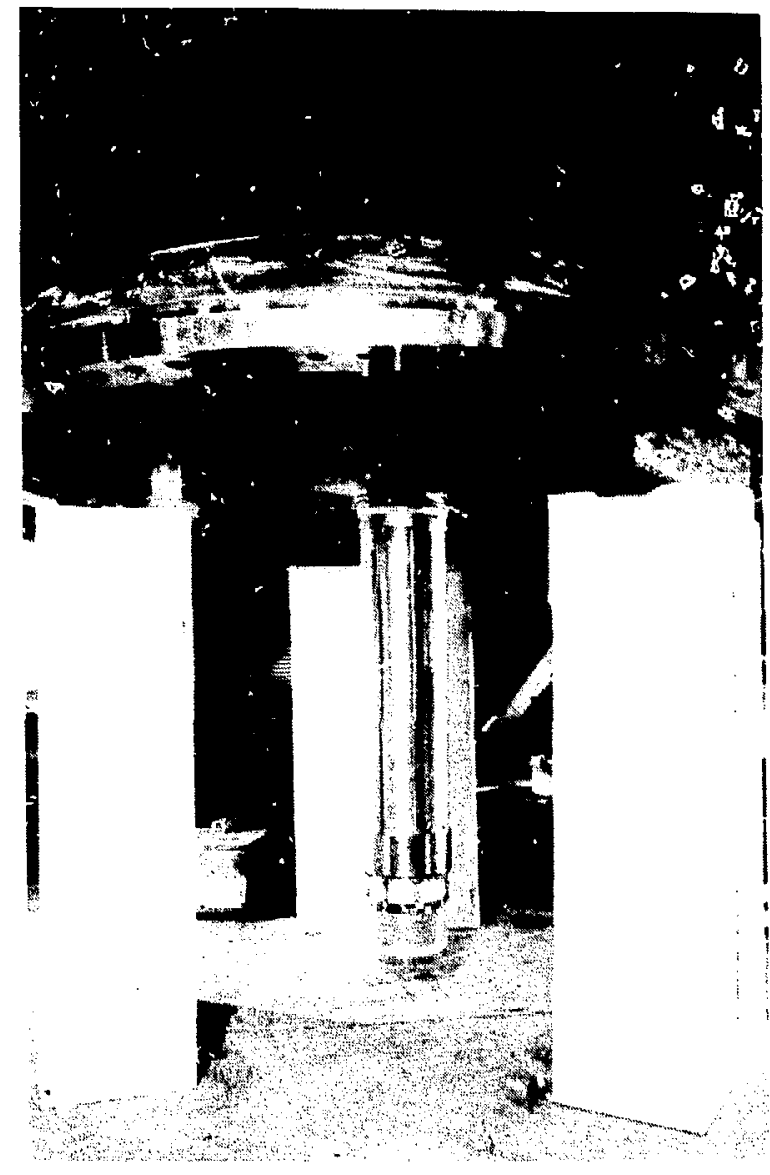

Fig. 11 Expansion piston. 


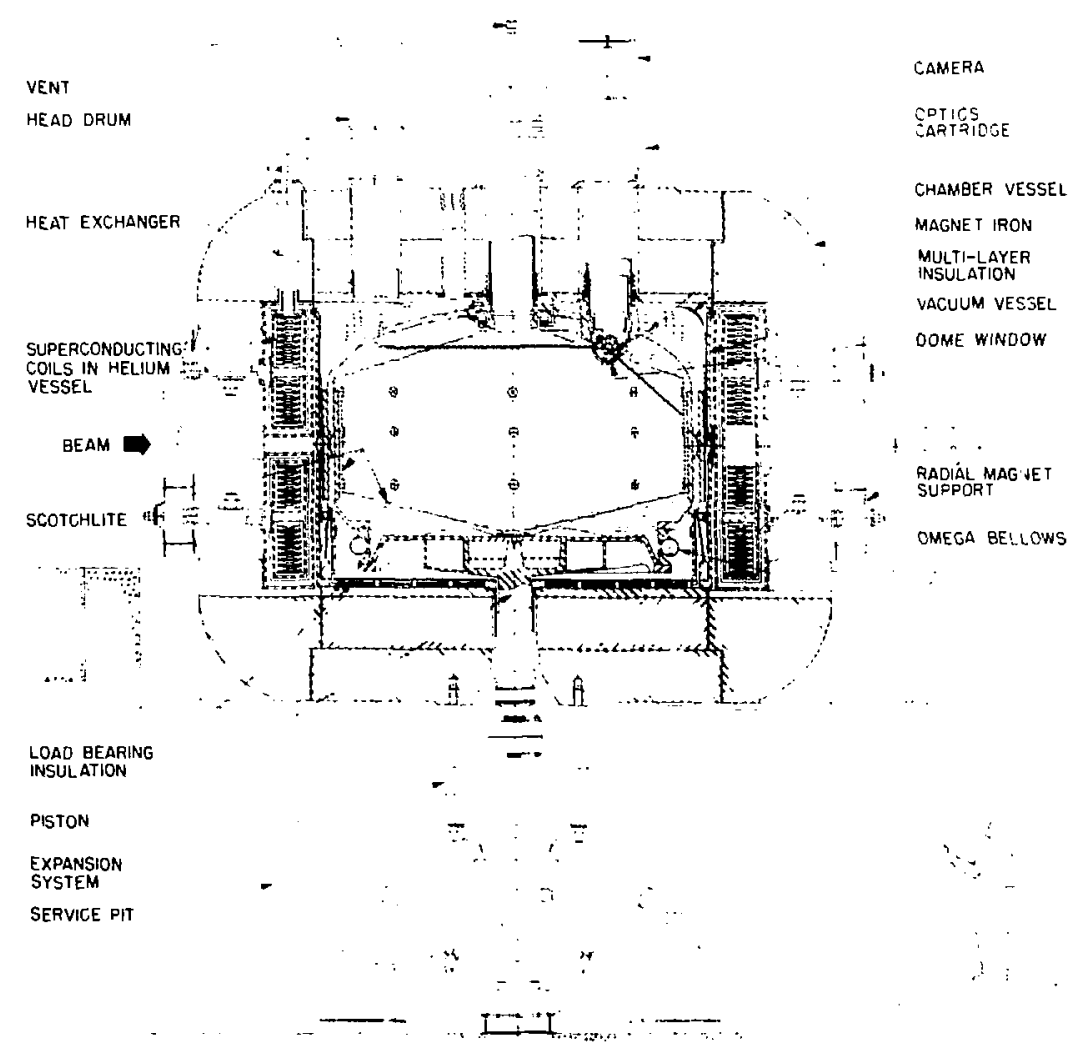

Fig. 12 Cross section of chamber and magnet. 


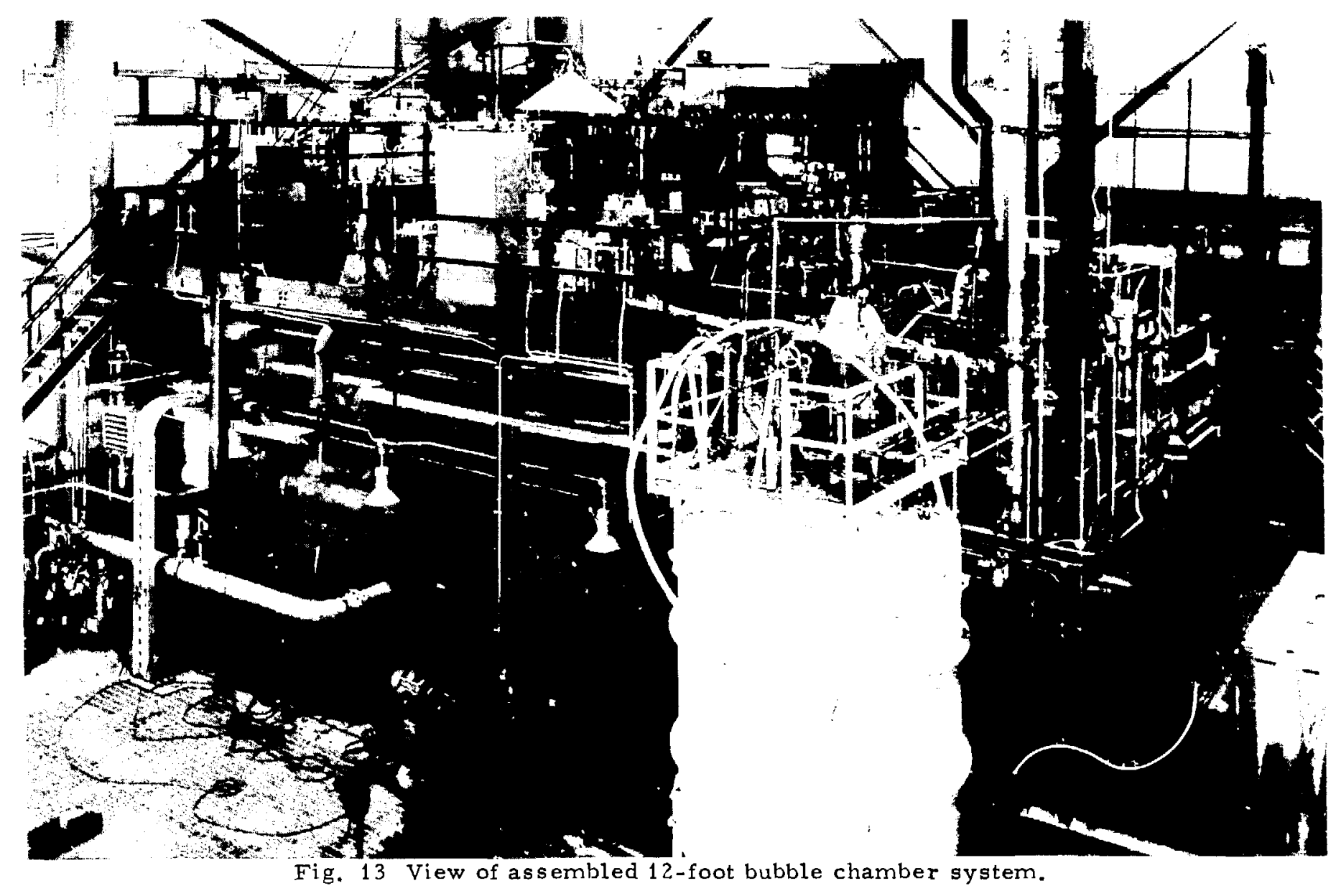




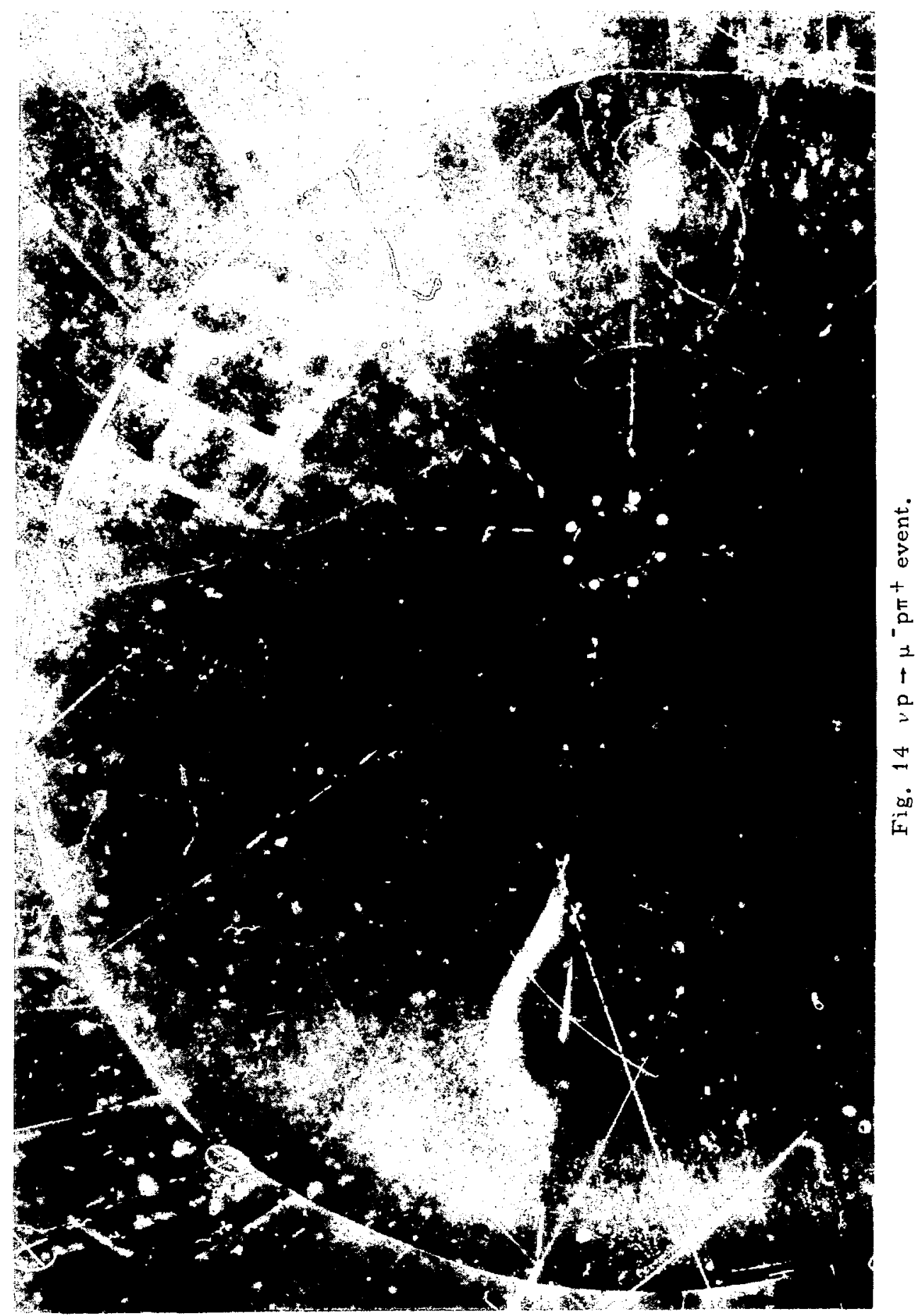




\section{CHAMBIRR OPFRATION}

Bob Picha was in chargc of hiring and training an operating crew. Tony Tamosaitis later took over this responsibility with Klaus Jaeger as the Deputy Group Leader. The superconducting magnet was installed in the fall of 1968 , prior to the installation of the bubble chamber. During tests of the magnet, it experienced two quenches. A plumbing modification was made, such that cold gas was returned at four points a round the top of the circumference of the magnet cryostat rather than the one location that was in the original design. We had no further problem, with the magnet after this change.

The chamber was first operated with liquid nitrogen in July, 1969. We were aided in this run by Paul Williams of the Rutherford Laboratory. The first hydrogen run was in October of 1969, when tracks were photographed. The major problems pointed up in this run was the lack of reliability in the expansion and the optics sys tems. The hydrogen compressor also lacked reliability and the helium refrigerator needed some improvement. These systems were worked on and another run was held in April, 1970, which showed some improvements were needed in the neutrino shield. In the summer of 1970 , these improvements were made, and in the fall, the first physics run was made with the chamber

Some milestones in the first ten years after approval in 1964 are given in Table $V$. The experiments carried out in the chamber 13 are listed in Table VI.

TABLE V. MILESTONES OF 12-FT BUBBLE CHAMBER PROJECT.

\begin{tabular}{|c|c|}
\hline $\begin{array}{l}\text { WISTORY OF CHAMBE? } \\
\text { JUNE } 1964\end{array}$ & LROPOSAL SUMITTES. \\
\hline JANUARY $20,19 E S$ & PRESIDEAT'S HDDSET FY:L. \\
\hline MAY 1965 & DESIGN STMRIES. \\
\hline Juive 1965 & SUPERMAGIVE T SLLLCTEE. \\
\hline ZWE IGEE & CONETPUCIION SIARTEI! \\
\hline DECEMBER $19 E 8$ & SUPERCOADUCTING MAGAE 'ESTR. \\
\hline AUS_ST I $35 \bar{y}$ & 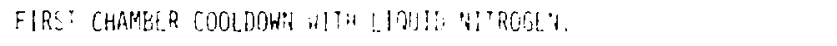 \\
\hline$x^{-}: E=: 35$ & 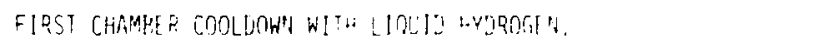 \\
\hline$E=-54 E=0 ; 37$ & FIRST EXPERIME NTAL PISTIRES TAKEN. \\
\hline HAFEEA 2975 & FIRST NEUTRIW: EVEHT IN LIAUID HYDROSEN. \\
\hline J6-3EF $197:$ & 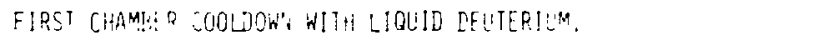 \\
\hline X'?.2ER 1971 & FIRST AE!!EIYU EVE IT IN LIGID DEUIERIUM. \\
\hline MQ6̈ 1972 & 1,000,000 FWYLS PICTURES TAKEN. \\
\hline MARCH 1972 & $\begin{array}{l}\text { IRACK SENS!IIVE EXPANSIONS IN THE DOURLE AHL IR!H.L PULSE MODE AT } \\
\text { INTERVALS AS CLOSE AS } 150 \text { MS. }\end{array}$ \\
\hline NOVEMBER 1973 & $\begin{array}{l}\text { FIRSI IRACK SENSIIIVE TARGEI (TST) RUN WITH HYDRI:ILN. TRACK } \\
\text { SENS ITIVE IHSIDE AND OUTSIDE TST AT } 27.5^{\circ} \mathrm{K} \text {. }\end{array}$ \\
\hline DECEMBER 1975 & $2,000,000$ PHYSICS PICTURES TAKEN. \\
\hline DECEMBER 1973 & $\begin{array}{l}\text { EXPANSION SYSTEM REACHED } 3,000,000 \text { PULSES WITH TIII SAME TOROIDAL } \\
\text { BELLOWS. }\end{array}$ \\
\hline
\end{tabular}


27

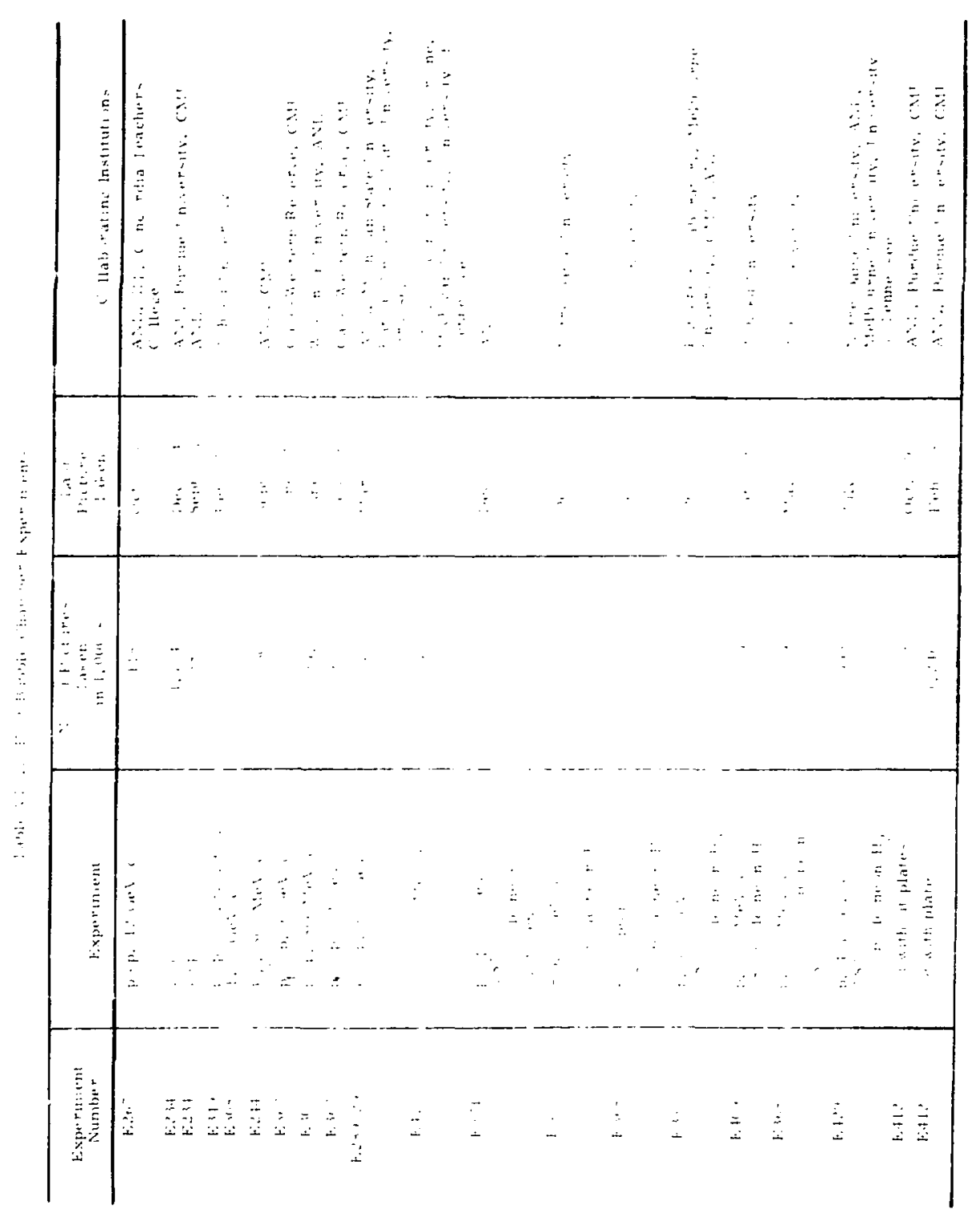


During the nine years it was in operation, a total of $6,948,000$ physics pictures were taken for 17 different experiments, and the overall picture-taking efficiency, including all downtimes for the chamber, beam, and Z.GS was $29 \%$. The yearly summary is given in Table VII. As can be seen, the chamber was operated with hydrogen, deuterium, a neon-hydrogen mixture, with a track-sensitive target and with a system of tantalum-plates for $\gamma$-conversion.

Table VII Yearly Summary of 12 -Foot Chamber Operation

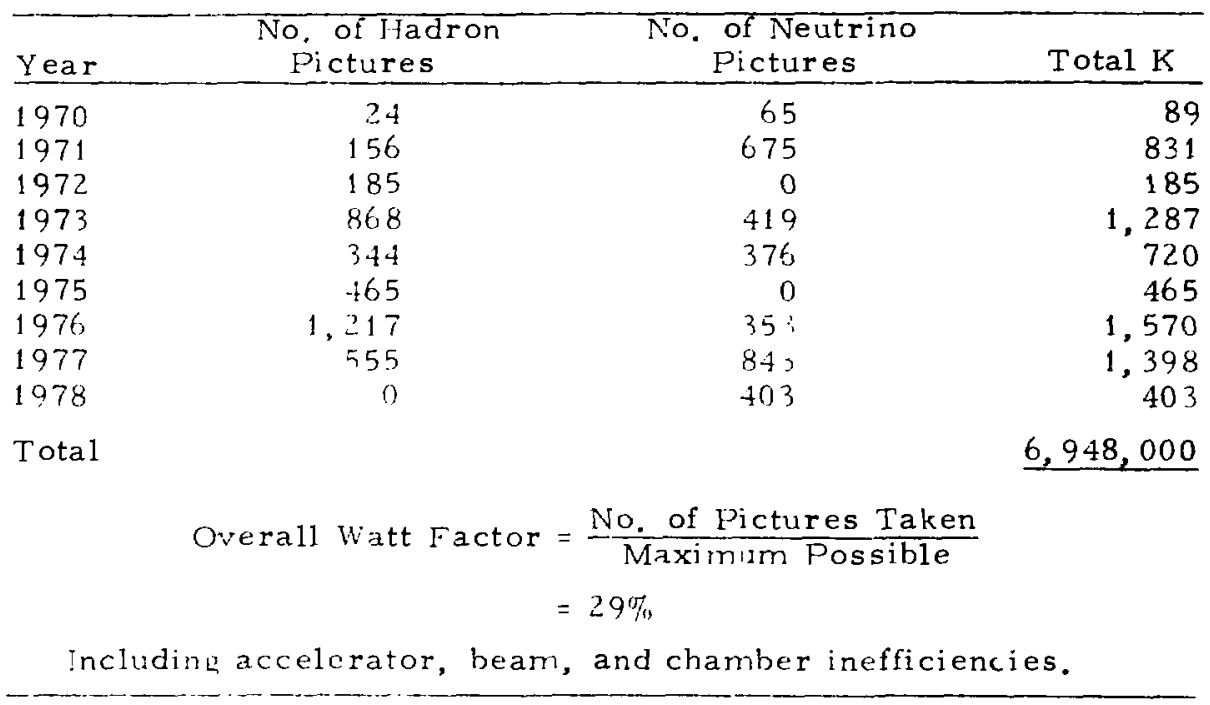

\section{NUYSICS HIGIILIGIHTS}

The chamber was planned with bouh neutrino physics and strong interaction studies in mind. The neutrino experiment was the first such experiment to be done using a liquid hydrogen or deuterium target, and the data obtained on the sample charged-current final states as $\mu^{-} p, \mu^{-} p \pi^{+}, \mu^{-} n \pi^{+}, \mu^{-} p \pi^{\circ}$ are still the best available. A notable early picture showed an example of associated production by the neutral current $\nu n \rightarrow \nu \wedge K^{\circ}$. A successful experiment to study the interactions and decays of low energy $\mathrm{K}^{\circ}$ mesons was also carried out.

In the strong interactions, the first experiment studying 12 $\mathrm{GeV}$ pp interactions started a minor industry of $\pi^{\circ}$ spectroscopy, using the relative good y conversion probability of the $\sim 2 \mathrm{~m} \gamma$-ray flight path available.

This work was foll wed up by similar studies using both high energy protons and low energy antiprotons in a track-sensitive target. Paul Kenney and his ccllaborators from Notre Dame were particularly active in the early planning for the use of this technique. 14 The TST program was done in a collaborative effort 
between Argonne, C.ERN, and the Rutherford Laboratory under the general direction of Klaus Jaeger.

\section{REFF,RENCES}

1. M. Derrick, J. Fetkovich, T. H. Fields, R. L. McIlwain, and G. Yodh.

2. R. Thompson and T. Fields, Bull. Am. Phys. Soc. 6, 24 (1961).

3. Proceedings of an International Conference on Instrumentation for High Energy Physics, p. 156, Interscience, New York 1960).

4. J. Kunzler, E. Buehler, F. Hsu, and J. Wernick, Phys. Rev. Lett. 6, 89 (1961).

5. The proposal from Avco Everett is dated April 1962 and had an estimated cost of $\$ 143,771$.

6. E. J. Lucas, 7..J.J. Stekly, C. Laverick, and E. G. Pewitt, International Advances in Cryogenic Engineering, p. $113(1964)$.

7. 7.J.J. Stekly, Advances in Cryogenic Engineering 8, 585 (1962).

8. C. Laverick and G. Lobell, Rev. Sci. Instr. 36, 825 (1965).

9. K. B. Martin, T. H. Fields, E. G. Pewitt, and J. G.

Fetkovich, Advances in Cryogenic Engineering 9, 146 (1963), U.S. Patent No. 3238574.

10. The proposed antiproton exposure was dropped since similar runs were made at Broukhaven and CERN in the period between submitting our proposal and the experimental run.

11. J. Purcell, "The Superconducting Magnet System for the 12Foot Bubble Chamber" - Design Report, ANL/HEP 6813; Colloques Internationaux Du Centre National De La Recherche Scientifique (Grenoble 1966). No. 166, p. 261, Editions Du Centre National De La Recherche Scientifique.

12. The people involved in the chamber design wrote a total of 167 internal Argonne technical memos called BBC Notes that described various phases of the project. Some general references in the open literature that describe the 12 -ft chamber are: M. Derrick, "Bubble Chambers 1964-1966", P. 431, Proceedings of the 1966 Instrumentation Conference on High Energy Physics. T. Fields, "Status of the Huge Liquid Hydrogen Bubble Chamber", Proceedings of the 1970 Dubna Conference on Instrumentation for High Energy Physics.

There are also a number of papers in the Proceedings of the International Conference on Bubble Chamber Technology, Ed. M. Derrick, Argonne 1970.

13. K. Jaeger, "Parameters and Performance Characteristics of the 12-Foot Bubble Chamber", ANL/HEP 7210.

14. K. Jaeger, "Performance of the Argonne 12-Foot Bubble Chamber", and $H$. Leutz, "Track Sensitive Target Construction and Operating Conditions", ANL/HEP 7414. 